\title{
FLOOD DAMAGE ASSESSMENT IN A GIS - CASE STUDY FOR ANNOTTO BAY, JAMAICA
}

\author{
H. GLAS ${ }^{1}$, S. VAN ACKERE 2 , G. DERUYTER ${ }^{1} \&$ P. DE MAEYER ${ }^{2}$ \\ ${ }^{1}$ Department of Civil Engineering, Ghent University, Belgium. \\ ${ }^{2}$ Department of Geography, Ghent University, Belgium.
}

\begin{abstract}
Natural hazards do not only affect millions of people, but also cause material damages up to 300 billion USD per year worldwide. The SIDS (Small Island Developing States) are characterized by an extremely high vulnerability to these hazards, due to their low-lying, densely populated cities and their fragile economy. To limit the consequences of these hazards, technocratic interventions do not suffice. Therefore, new approaches that focus on flood risk management are developed. In this context, Annotto Bay, Jamaica, was chosen as a case study area to perform a flood damage assessment. In this study, a flood damage map was created for the 2001 flood caused by Tropical Storm Michelle. This map focuses on three types of damage: building, road and crop damage. The first type was calculated using the exact GPS locations of the buildings, as well as average replacement values for each building type and flood damage functions. The total building damage was then combined per land-use polygon to have an orderly visual view of the damage spread. Furthermore, the road damage was calculated, based on a road network extracted from satellite imagery. In a next step, as buildings are mostly located in proximity of roads, buffers were created around the road network, resulting in a more accurate visual view of the building damage spread. Then the crop damage was calculated based on maximum damage values for banana plantains and other crops, combined with the crop damage functions. The final result is a total damage map, visualizing the location of high risk areas with a high accuracy. Additionally, the total calculated damage was compared to the actual damage caused by the 2001 flood. This comparison shows promising results.
\end{abstract}

Keywords:damage map, flooding analysis, natural hazards, risk assessment.

\section{INTRODUCTION}

In the last two decades, the growing frequency and intensity of natural hazards introduced 'the era of catastrophes' [1]. The 2004 tsunami in Thailand, the 2010 earthquake in Haiti, and the 2015 earthquake in Nepal are only a few examples of natural disasters that hit these countries at social, economic, and political levels, due to devastating human and material losses. These irregular, large-scale events are not the only ones that can debilitate communities. Yearly flooding in the UK, for example, causes economic damages up to 250 million dollars [2]. To make matters worse, these damage numbers will only grow in the future, due to climate change and its associated increase in severity and frequency of hazards[3].Although natural hazards occur in developed countries as well as in developing countries, the disaster risk is disproportionately concentrated in low- and middle-income states, in particular in the small island developing states (SIDS)[4]. The extreme vulnerability is caused by the lowlying, densely populated cities and the fragile economy, characterising these regions[5]. 
Flooding affects more people worldwide than any other hazard[6]. Technocratic interventions to prevent damage, such as dams, levees, and flood forecasting, have shown limited success in the past $[3,7]$. In order to truly minimize the socio-economic cost induced by inundations, an adequate flood risk assessment is necessary to compute the damage of future floods as accurately as possible. Since the SIDS are expected to lose 20 times more of their capital stock in disasters each year, than Europe and Central Asia [4], these new approaches that indicate high risk areas are indispensable to help decision makers to better allocate their limited resources and funds to limit the consequences of flooding, rather than to prevent flooding from occurring [7].

In this research, a damage map was created as a first step towards such a risk-based approach. Maximum damage values, or replacement values, were multiplied with a damage factor to calculate the real damage cost. This damage factor is the percentage of damage to an element at risk for a certain flood level. In order to perform this assessment, flood data and land-use values were acquired.

\subsection{Case study area}

Jamaica, one of the SIDS, suffers regularly from severe flooding. Over a period of four years, the estimated economic damages due to inundations were estimated at 1.5 billion USD [8]. Annotto Bay, a coastal town in the north-east of the island, has a low-lying urban area, with approximately 5,500 inhabitants. Combined with its location downhill from the Blue Mountains and four rivers traversing the city, this topography indicates an extreme vulnerability to severe inundations. Moreover, the alluvial deposits in the soil cause flash floods to happen, even after very short periods of precipitation in the mountains [9]. Therefore, Annotto Bay was chosen as a case study area for this flood damage assessment. Figure 1 shows the land use in the town, as well as the location of the main roads and buildings.
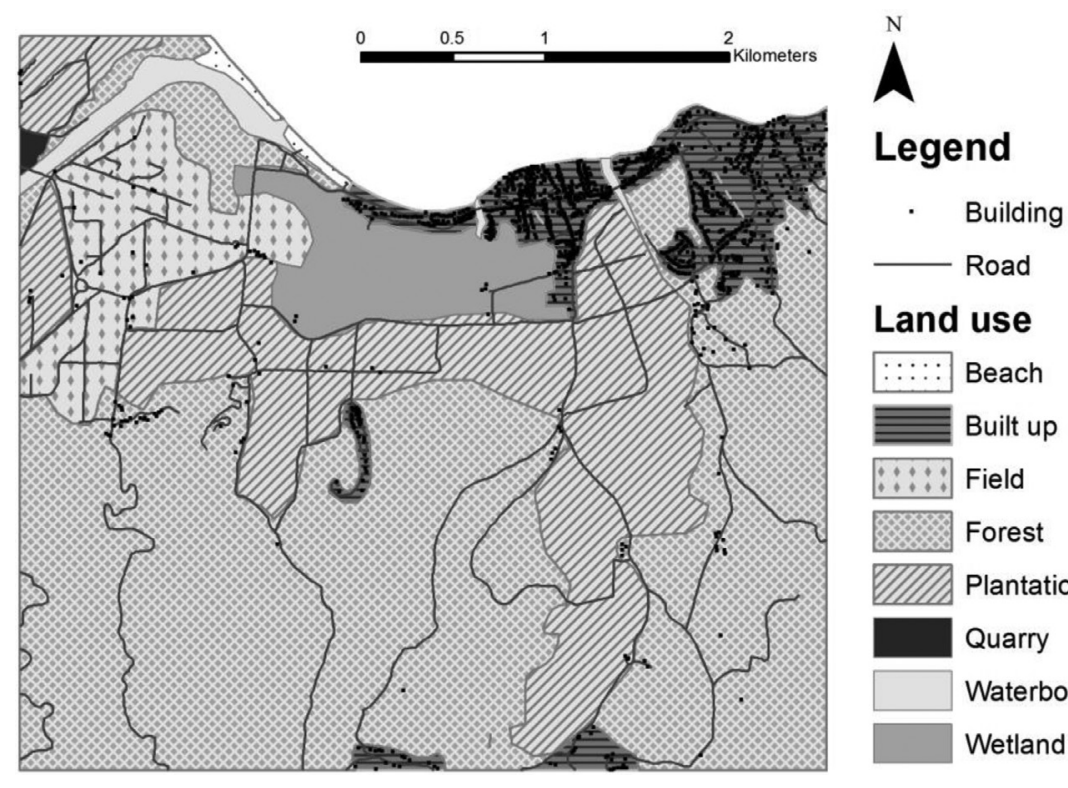

\section{Land use}

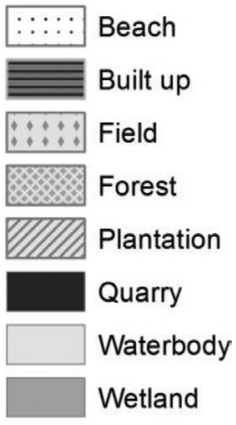

Figure 1: Annotto Bay land-use map. 


\section{METHODS}

The approach that was used to create the final damage map for Annotto Bay is based on three types of input data, as can be seen in Fig. 2. The first type is the land-use data, or elements at risk, which can include building locations, the road network and agricultural information. The level of detail of this data determines the level of detail of the resulting damage map. The second type of input information is the economic data. This type comprises the replacement values for all land use. A replacement value is the cost to replace an element at risk after it has been completely destroyed. The last type of input data is the flood data. In this case, to create one damage map, the flood extent of the flooding caused by Tropical Storm Michelle in 2001 was used. During this storm, a large area of the town was inundated for a period of two days and many elements at risk were damaged.

By combining the replacement values with the land-use data, a maximum damage map was generated, showing the damage in the area if the flooding would destroy 100 percent of the elements at risk. This map was then combined with the flood data, using damage factors per land-use type. Consequently, the Resulting damage map shows the damage for a location, based on the element at risk and its economic value at that location for the given flood level.

This process was carried out for the three types of damage: building, road and crop damage, since the input data and calculation methods for each type differ immensely. In a final step, the separately calculated damages were combined to generate an overall damage map.

\subsection{Input data}

In developing countries, data availability is a major issue [11].Therefore, the data acquisition is in many cases time-consuming. However, since ODPEM[9] has performed a multi-hazard risk assessment in the area in 2013, most land-use data were already acquired. Table 1 lists the data that were used in this research. Although a road dataset was available, the road network was extracted from satellite imagery, because the original dataset was incomplete, as many dirt roads were not included. Even though the damage to these roads is minimal, they do provide access to buildings, making them an important visual and spatial element.

Since the elements at risk can be divided into three groups, buildings, roads and crops, three types of replacement values were acquired. ODPEM [9] provided average building values for different building materials. By adding the number of floors, available in the

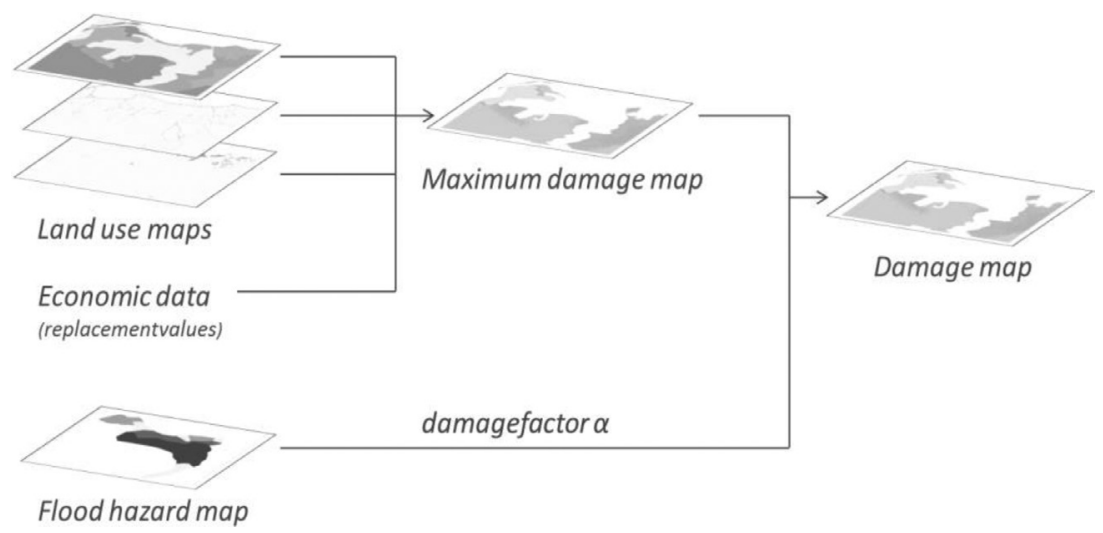

Figure 2: General methodology for Annotto Bay damage assessment [10]. 
building location data, the total cost of each building was determined. Average crop values were acquired from FAOSTAT [14]. To determine the last replacement value, for roads, an average cost for developing countries was used [15].

Tropical Storm Michelle induced heavy precipitation in the mountains, resulting in flash floods downstream [9]. Annotto Bay suffered from flooding up to 4 feet over a period of two days. A flood map was drawn of the maximum flood extent during these 48 hours. This map, shown in Fig. 3, was used as input flood data in the damage assessment. Since this map only shows water heights, the velocity was not taken into account in the calculations.

The flood map and the maximum damage, calculated by combining land-use data and replacement values, are merged using damage factors, extracted from depth-damage functions. The depth-damage functions for buildings and crops were acquired from Dutta et al. [16]. These functions were drafted for Japan, but since this island shows similar cultural, geographical and topological characteristics, they were transferred to Jamaica.

Table 1: Input land-use data.

\begin{tabular}{lcl}
\hline Data & Type & \multicolumn{1}{c}{ Source } \\
\hline Land use & Polygon & $\begin{array}{l}\text { NLA [12] + update based on DigitalGlobe satellite } \\
\text { imagery [13] }\end{array}$ \\
Road network & Polyline & Based on DigitalGlobe satellite imagery [13] \\
Buildings & Point & ODPEM [9] \\
Critical buildings & Point & ODPEM [9] \\
\hline
\end{tabular}

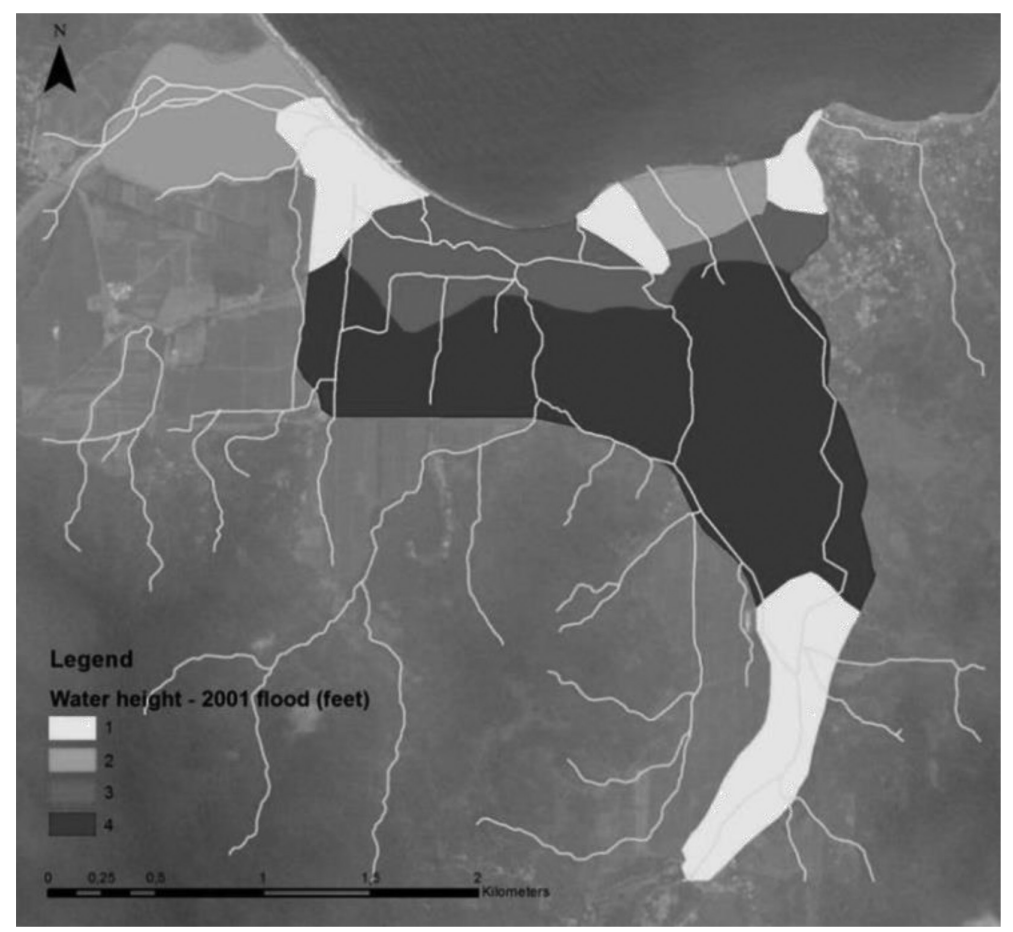

Figure 3: Flood extent of 2001 inundations caused by Tropical Storm Michelle in Annotto Bay, Jamaica [11]. 


\subsection{Building damage}

Since the exact locations, building materials and number of floors are known for all buildings in Annotto Bay (see 2.1), an adequate damage assessment could be performed. With the use of average building areas and material costs, a maximum damage value per building was calculated. Using the point damages as such in the visualisation would lead to a visual underestimation of the total damage, since the damaged points would seem very small in comparison to the entire study area. In order to generate a better visual result and facilitate the interpretation of the damage map, the building point features were aggregated per land-use polygon. All damage values of all buildings in one polygon were added up to one building damage value per land-use polygon, creating damage zones. The polygon layer was then combined with the damage factors, based on Duttaet al. [16] to create the building damage map.

Every building must be accessible from a road. This assumption was applied in this assessment by creating two buffers around the road network, at 25 meters and at 60 meters. Samples in the study area showed that 90 percent of all buildings are located in the 25 meter buffer and 99 percent in the 60 meter buffer. The visual result of this adaption is illustrated in Fig. 4. The spatial distribution of building damage is more accurate and high risk areas are distinctly indicated. Especially large land-use polygons without any damage except building damage, for example in the wetland areas, benefit immensely from these buffers.

\subsection{Road damage}

A road dataset of the area was available for this research, giving a class and corresponding width to each road [17]. Although this information allowed a more precise damage calculation, a comparison with satellite imagery showed big disparities between the available dataset and the reality. Many dirt roads were missing and the simplification of the data, due to its larger scale, caused the location of other roads to differ from reality. Additionally, damage to roads showed to be significantly smaller than building damage. Therefore, the priority was given to adding all dirt roads and losing the class information to enhance the accuracy of the building damage spread.

The road damage was calculated by multiplying the average replacement value [15] with a damage factor. This factor is based on calculations for LATIS, a Flemish flood model [7]. Since no road classes were used, an average width was assigned to each road to calculate the damage per square meter.The roads are thus visualised as polygons in the final damage map.
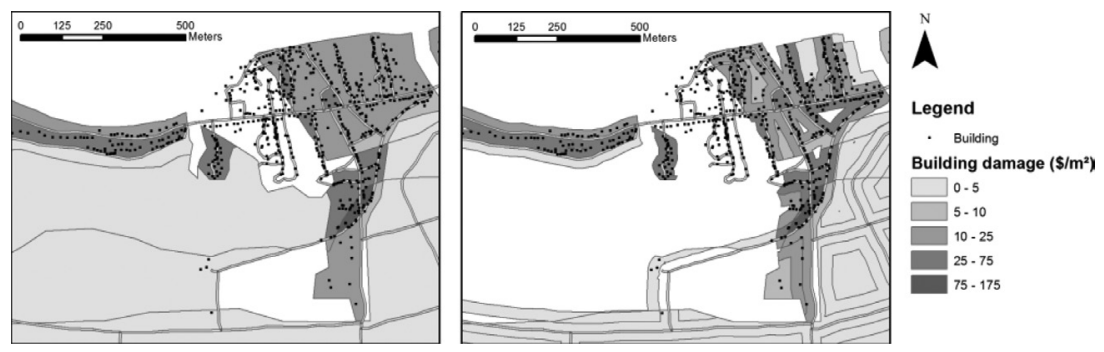

Figure 4: Visual comparison between building damage calculations without buffers (left) and with buffers (right). 


\subsection{Crop damage}

Finally, the crop damage was calculated. Since the available land-use data distinguishes banana plantains from other crops, two different damage functions were used. For the former, a damage factor of $100 \%$ was used, since banana plants have a fragile root that cannot survive a 48 hour flood.In Duttaet al.[17], all crops were selected that were also found in the study area. An average of these damage factors was used for the latter land-use type.

To calculate the damage, replacement values needed to be acquired. From FAOSTAT[14], average values for the same crops as in the damage factor calculations, were gathered and combined into one value. Furthermore, the value of banana plants was acquired. Hence, these values were multiplied with the damage factors to generate the crop damage.

\section{RESULTS}

Before generating the final damage map for Annotto Bay, the three types of damage are visualised separately in Fig. 5. The cost of each type of damage and the damaged area is given in Table 2. It is immediately clear that the building damage cost is substantially higher than

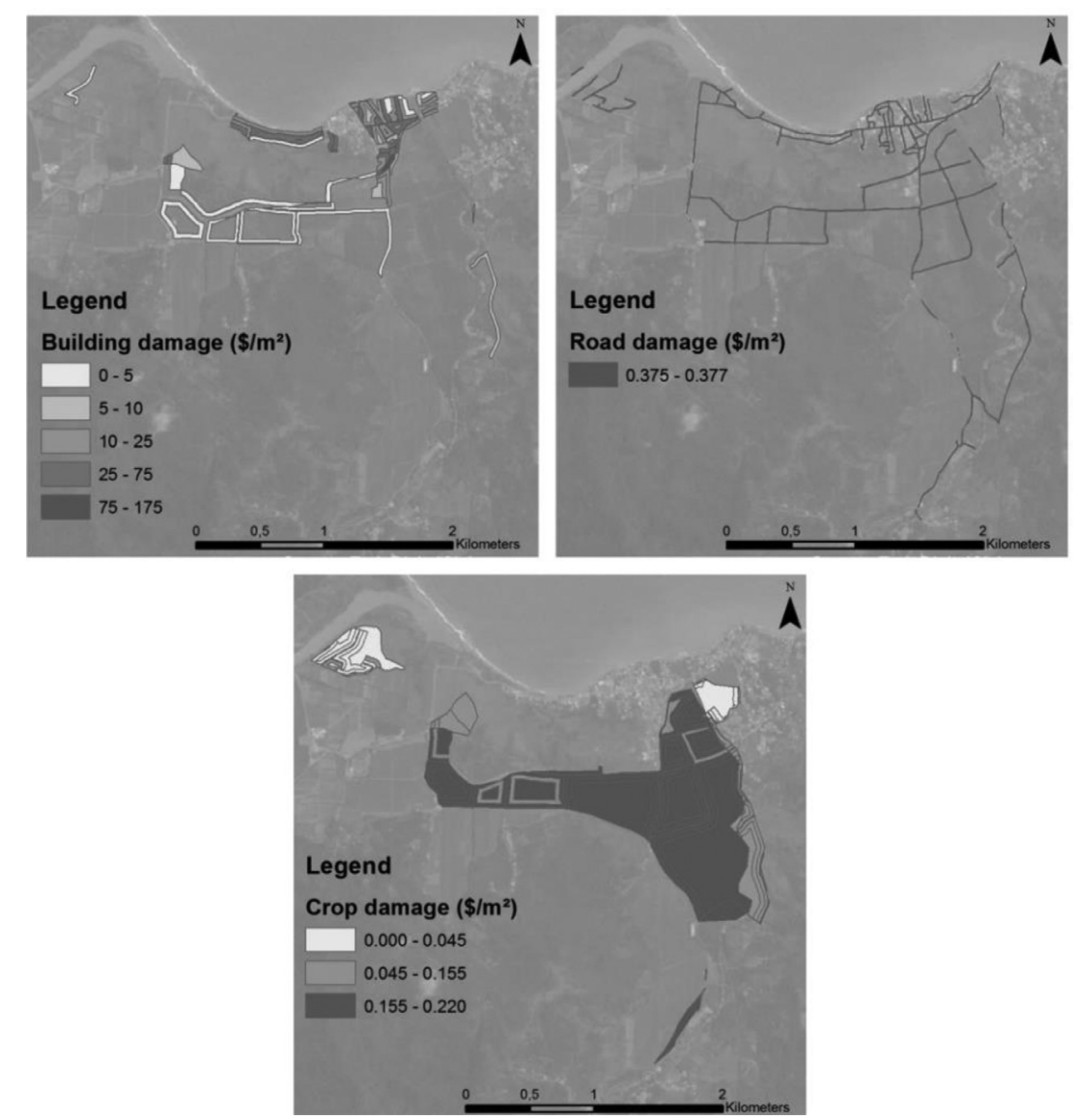

Figure 5: The damage maps for the 2001 flood in Annotto Bay, Jamaica, per damage type. (top left: building damage, top right: road damage, bottom: crop damage). 
the cost of the other two types, while the crop damage has the largest spread. The total damaged area is not equal to the sum of the areas per damage type, since some polygons contain more than one type. For example, rural areas with housing will have building damage as well as crop damage.

As a result of the use of the two buffers for building locations, the total damaged building area is limited. Without the buffers, the damaged area for buildings would be $1857396 \mathrm{~m}^{2}$. However, when only looking at the average building area of the houses that were damaged, the building area of the damaged houses is only $132903 \mathrm{~m}^{2}$. Hence, the buffers still cause an overestimation of the damaged building area, but the result is much closer to the reality.

In a next step, the final damage map was generated, by adding up the three separate damage types. This map is shown in Fig. 6. Due to the high damage values of buildings, the

Table 2: Overview of damage cost and damaged area per damage type.

\begin{tabular}{lcc}
\hline Damage type & Damage cost $(\$)$ & Damaged area $\left(\mathrm{m}^{2}\right)$ \\
\hline Building damage & 7083291 & 522983 \\
Road damage & 51210 & 136284 \\
Crop damage & 371787 & 2049042 \\
Total damage & $\mathbf{7 5 0 6 ~ 2 8 8}$ & $\mathbf{2 4 5 8 7 0 2}$ \\
\hline
\end{tabular}

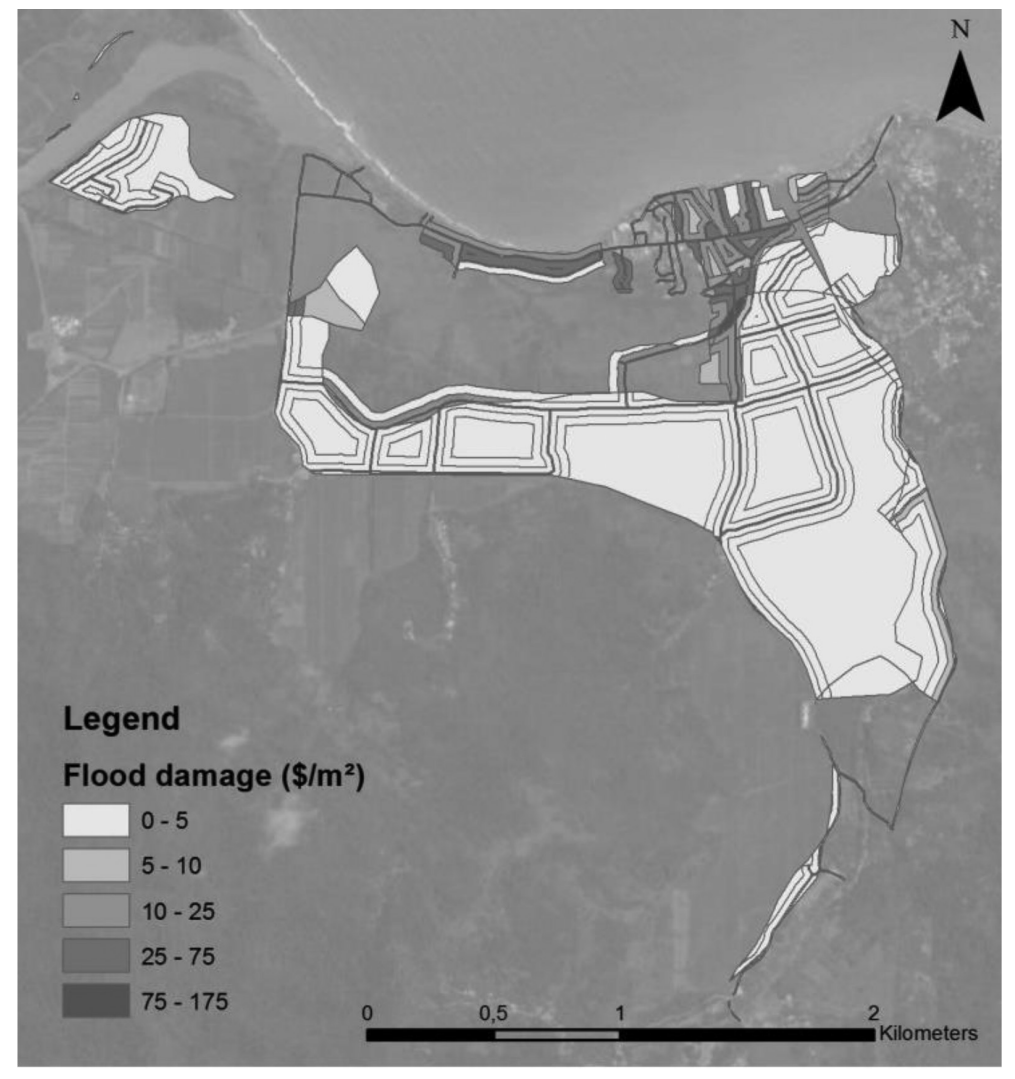

Figure 6: Final damage map for the 2001 flood in Annotto Bay, Jamaica. 
distinction in crop damage has disappeared. However, it is clear that the high-risk areas are located in the low-lying urban areas and along the main road, parallel to the coastline. The wetland does not have any damage, except for the buffers along the roads, since only a few houses are located there.

With a maximum damage cost of $175 \$ / \mathrm{m}^{2}$, this flooding has not completely destroyed any houses, considering that the replacement value of buildings is on average $836 \$ / \mathrm{m}^{2}$.

\section{DISCUSSION AND CONCLUSION}

This damage assessment was executed as a first step towards a generic flood risk assessment in the SIDS. Hence, the focus was on developing a tool that can be used in other regions as well. The main goal was to visualize the high-risk areas and give an adequate estimation of the damage. Therefore, the preference was given to a road dataset based on satellite imagery of DigitalGlobe [13], rather than using the available road data with classes. This new dataset has lent the opportunity to add buffers that localise the buildings more precisely. Given that the building damage cost is the biggest share in the overall cost, this approach offered a better visual result. When this approach is used in future study areas, the buffers around the road network will help to better allocate building damage, even when the land-use data are less detailed.

By comparing the results of this flood tool with the real damage values, the accuracy of the assessment is tested. However, information about the damages done by the 2001 flood are hard to find. According to the multi-hazard risk assessment report of ODPEM[9], the number of affected houses is 749 , or $46 \%$. In this damage assessment, 799 houses, or 49\%, are estimated to be affected. The small overestimation could be expected, since all houses in a certain flood level are assumed to be equally affected by the inundation. In reality, however, some houses will resist better and they will thus have less damage or no damage at all. No information was available about the damage cost to the buildings due to the flood, so this aspect could not be compared.In order to test the accuracy of the calculated damage costs, more information about the actual damages and corresponding costs, caused by the inundations, is necessary in further research.

When looking at road damage, the ODPEM report states that $3.5 \mathrm{~km}$ of the main roads were damaged during the 2001 flood [9]. This number is impossible to compare with the results of the road damage assessment, since the road dataset that was used does not make a distinction between main roads, secondary roads and dirt roads. According to the flood tool, $22.7 \mathrm{~km}$ of roads are affected by the inundations. Since the total road damage cost is a very small share of the total damage cost, the accuracy of this result and the importance of these calculations can be questioned, but the roads do give access to buildings and serve as evacuation routes during disasters. One could argue that the road damage cost can be neglected in urban areas, where building damage takes up a much larger part of the total damage. In rural areas, however, the road damage cost and crop damage cost are within a similar order of magnitude. Hence, further research should focus on the importance of the road damage calculations in these rural areas to determine if future flood damage analysis should only take into account the accessibility of roads, rather than the accurate damage cost.

While ODPEM noted a damaged crop area of $620000 \mathrm{~m}^{2}$ [9], the flood tool calculated an area of $2049042 \mathrm{~m}^{2}$. This difference is mainly due to the crops that were taken into account in both calculations. The report only has numbers for a limited amount of crops. The tool, however, generated a result for all crops. Unfortunately, the damage cost for crops was not available. A useful comparison could thus not be made. Furthermore, the cost of crop damage is insignificant in comparison to building damage, since Annotto Bay is an urban area. A rural 
area, where more crop data are available, should be tested in the future to decide on the reliability of the crop damage calculations of this flood tool, visually as well as quantitative.

Although the exact damage costs could not be examined on their correctness, the visual result does give a correct view on the damage spread and the areas with the highest damage. The high-risk areas are clearly indicated and correspond to the areas that were affected most by the 2001 flood. Hence, this methodology can be used by decision makers as a qualitative tool. The quantitative results must be tested further to determine their adequacy. The focus of future research must be on study areas with sufficient information of past flood events and the corresponding damages. As many values used in the flood tool, are averages or estimations, this step is indispensable to create an accurate, quantitative flood damage assessment, usable in all SIDS.

\section{ACKNOWLEDGEMENTS}

The authors would like to thank ArpitaMandal and Sherene James-Williamson from the University of the West Indies, campus Mona, Department of Geography for their help in acquiring the necessary data.

\section{REFERENCES}

[1] Kunreuther, H.C., Michel-Kerjan, E.O., Doherty, N.A., Grace, M.F., Klein R.W. \& Pauly, M.V., At War with the Weather. Managing Large-Scale Risks in a New Era of Catastrophes, The MIT Press, pp.xiiv-xvii, 2009. http://dx.doi.org/10.7551/mitpress/9780262012829.001.0001

[2] Penning-Rowsell, E.C., A realistic assessment of fluvial and coastal flood risk in England and Wales.Transactions of the Institute of British Geographers, 40(1), pp. 44-61, 2014. http://dx.doi.org/10.1111/tran.12053

[3] Gall, M., Borden, K.A., Emrich, C.T. \& Cutter, S.L., The unsustainable trend of natural hazard losses in the United States.Sustainability, 3(11), pp. 2157-2181, 2011. http://dx.doi.org/10.3390/su3112157

[4] United Nations Office for Disaster Risk Reduction (UNISDR), Making development sustainable: the future of disaster risk management. Global Assessment Report on Disaster Risk Reduction. UNISDR, pp. 1-266, 2015.

[5] UNESCO, Changing small island developing states: A space perspective on environmental change in the Caribbean, UNESCO, pp. 1-122, 2014.

[6] International Strategy for Disaster Reduction (ISDR), Global Assessment Report on Disaster Risk Reduction, ISDR, pp. 5-10, 2009.

[7] Deckers, P., Kellens, W., Reyns, J., Vanneuville, W. \& De Maeyer P., A GIS for flood risk management in Flanders.Geospatial Techniques in Urban Hazard and Disaster Analysis, Springer: The Netherlands,pp. 51-69, 2010.

[8] Office of Disaster Preparedness and Emergency Management (ODPEM), National progress report on the implementation of the hyogo framework for action (2011-2013), ODPEM, pp. 1-47, 2013.

[9] Office of Disaster Preparedness and Emergency Management (ODPEM), Multi Hazard Risk Assessment Annotto Bay, St. Mary, ODPEM, pp. 1-158, 2013.

[10] Glas, H., Jonckheere, M., De Maeyer, P. \& Deruyter, G., Risk assessment in the Caribbean: modeling a GIS-based flood risk tool for Jamaica.First Young Researchers Overseas' Day, pp. 1-8, 2014. 
[11] Glas, H., Jonckheere, M., De Maeyer, P. \& Deruyter, G., A GIS-based flood risk tool for Jamaica: the first step towards a multi-hazard risk assessment in the Caribbean. 15th International Multidisciplinary Scientific Geoconference SGEM 2015 - Conference Proceedings Volume II, STEF92 Technology Ltd.: Albena, Bulgaria, pp. 643-650, 2015.

[12] The National Land Agency of Jamaica (NLA), Landuse Jamaica, NLA, 2001.

[13] DigitalGlobe, World Imagery (Jamaica), 8/8/2010.

[14] FAOSTAT, Food and Agriculture Organization of the United Nations: Statistics Division (foastat3.fao.org/download/Q/*/E: foastat3.fao.org/download/Q/*/E), 2014.

[15] Collier, P., Kirchberger, M. \& Söderbom, M., The Cost of Road Infrastructure in Developing Countries, Centre for the Study of African Economies, Derpartment of Economics, Oxford, 2013.

[16] Dutta, D., Herath, S. \& Musiake, K., A mathematical model for flood loss estimation. Journal of Hydrology, 277(2), pp. 24-49, 2003. http://dx.doi.org/10.1016/S0022-1694(03)00084-2

[17] WRA, Jamaica Road Network, 2007. 